\title{
"EIS QUE (QUASE) TUDO SE FEZ NOVO": O CARISMATISMO CATÓLICO E AS RESSIGNIFICAÇÕES DA TRADIÇÃO NO EVENTO CRISTO É NOSSO SHOW
}

\author{
"The old has (almost) gone, the new is here": Catholic charismatism and the \\ resignifications of tradition in the event Christ is Our Show
}

Brandon Lopes dos Anjos ${ }^{1}$
Lara Pazinato Nascimento $^{2}$
Frank Antônio Mezzomo $^{3}$
na Satiê de Oliveira Pátaro

Resumo: Objetivamos analisar as ressignificações da tradição católica no evento Cristo é Nosso Show, realizado em Campo Mourão, Paraná, que tem como elemento marcante as celebrações carismáticas. A festa, que ocorre no município anualmente desde 2003, é considerada a principal festividade da Diocese de Campo Mourão, e conta em sua programação com shows e pregações realizadas por personalidades reconhecidas no meio gospel. Os procedimentos metodológicos empregados nesta pesquisa envolveram trabalho de campo durante a $15^{\text {a }}$ edição do evento, realizada em novembro de 2017, para observação da configuração da festa e coleta de entrevistas com os participantes. Com base no material levantado foi possível observar como os fiéis se sentem atraídos pelas formas de adoração, com pregações e louvores de caráter emocional, em uma confluência e ressignificação entre elementos tradicionais e contemporâneos. A partir das falas dos entrevistados, notamos como a celebração carismática é compreendida como uma forma alternativa às missas habituais, sem deixar de lado o respeito e apreço pela liturgia. A combinação entre o tradicional e o renovado trazida pelo evento Cristo é Nosso Show demonstra uma ressignificação da tradição católica que é expressada em uma linguagem atualizada, funcionando de modo a oferecer novas formas de engajamento aos fiéis, bem como atrair novos seguidores.

Palavras-chave: Carismatismo católico; Igreja Católica; Cristo é Nosso Show; Tradição e Modernidade; Ressignificações.

\begin{abstract}
Our objective is to analyse the resignifications of the Catholic tradition in the Christ is Our Show event held in Campo Mourão, Paraná, which has charismatic celebrations as one of its main characteristics. The festival, which takes place annually since 2003, is considered the main festivity of the Diocese of Campo Mourão, and has a line-up of concerts and preaching performed by renowned characters of the gospel scene. The methodological procedures employed in this research involved fieldwork during the 15th edition of the event, held in November 2017, in order to observe the setting of the festival and to collect interviews with its

\footnotetext{
1 Graduando em História pela Universidade Estadual do Paraná (Unespar), bolsista de iniciação científica (Fundação Araucária). E-mail: brandon.njos@gmail.com

2 Mestranda do Programa de Pós-Graduação Interdisciplinar Sociedade e Desenvolvimento (PPGSeD) pela Universidade Estadual do Paraná (Unespar). E-mail: larapazinato@ gmail.com

${ }^{3}$ Doutor em História. Professor do Programa de Pós-Graduação Interdisciplinar Sociedade e Desenvolvimento (PPGSeD) da Universidade Estadual do Paraná (Unespar). E-mail: frankmezzomo@ gmail.com

${ }^{4}$ Doutora em Educação. Professora do Programa de Pós-Graduação Interdisciplinar Sociedade e Desenvolvimento (PPGSeD) da Universidade Estadual do Paraná (Unespar). E-mail: crispataro@ gmail.com
} 
participants. Through the material collected it was possible to observe how the faithful are attracted by the forms of worship, with emotional preaching and praises, in a confluence and resignification between traditional and contemporary elements. From the speeches of the interviewees, we note how the charismatic celebration is understood as an alternative to the usual Masses, without neglecting the respect and appreciation for the liturgy. The combination of the traditional and the renewed brought by the event Christ is Our Show demonstrates a resignification of the Catholic tradition, which is expressed in an updated language, functioning as a means of offering the faithful new ways of engagement, as well as attracting new followers.

Keywords: Catholic charismatism. Catholic Church. Christ is Our Show. Tradition and modernity. Resignifications.

\section{Introdução}

O Cristo é Nosso Show é realizado anualmente desde 2003 na cidade de Campo Mourão, Paraná. Considerado o "principal evento católico da diocese de Campo Mourão"5 (BONETE, 2017), já trouxe em suas edições reconhecidos nomes ligados ao catolicismo, como Frei Rinaldo, Reginaldo Manzotti, Fábio de Melo, as bandas Anjos do Resgate e Rosa de Saron, entre outros. Conhecendo a importância que o evento possui para os fiéis católicos da região, objetivamos investigar como este expressa uma linguagem contemporânea da tradição católica por meio de celebrações carismáticas, e quais são as percepções dos fiéis acerca de tal configuração religiosa, oriunda da atuação da Igreja em um cenário secularizado.

Considerada uma das bases da sociedade moderna, a secularização se caracteriza pela emancipação do poder temporal da guarda religiosa. No entanto, como pondera Hervieu-Léger (2008), este processo não implica a irreligiosidade do indivíduo, mas uma reconfiguração das crenças, produzidas ou adaptadas, para suprir as expectativas e incertezas surgidas no bojo da modernidade. Com isso, há um arrefecimento do monopólio espiritual que até então pertencia às grandes Igrejas, e uma expansão de novas crenças que se proliferam, sejam estas novas formas de religiosidade ou apropriações e ressignificações das tradições religiosas.

Deste modo, segundo Hobsbawn e Ranger (2006, p. 13), as tradições se adaptam quando é necessário, para "conservar velhos costumes em condições novas ou usar velhos modelos para novos fins". Se quiséssemos buscar um marco temporal para ressignificação e atualização da tradição católica, talvez o movimento impulsionado pelo Concílio Ecumênico Vaticano II (1962-1965), expresso já na convocação do evento, feita pelo Papa João XXIII, dá o diapasão

\footnotetext{
${ }^{5}$ A diocese de Campo Mourão conta com 41 paróquias, estabelecidas em 26 cidades, abrangendo as microrregiões de Campo Mourão, de Goioerê (exceto Altamira do Paraná) e parte da de Cianorte (exclusivamente por Jussara) (DIOCESE DE CAMPO MOURÃO, 2012).
} 
das mudanças: "pôr em contacto com as energias vivificadoras e perenes do evangelho o mundo moderno" (Humanae Salutis, 1961:3), e, com isso, "conciliar a presença e atuação da Igreja com os novos tempos" (MENDES, 2012, p.153). De acordo com Sanchez (2017) e Mendes (2012), o Concílio Vaticano II apresenta um aggiornamento, caracterizado pela revisão dos antigos dogmas à luz das sagradas escrituras, bem como uma abertura às afirmações terrestres e sua autonomia, ao ecumenismo, às religiões não cristãs, além de reconhecer os direitos humanos e se disponibilizar para dialogar com a ciência. De tal modo, a Igreja pretendeu assegurar sua ação no mundo e manter sua posição de influência naquele novo quadro social da modernidade.

É nesse contexto de maior flexibilidade do catolicismo que nasce a Renovação Carismática Católica (RCC), originada nos Estados Unidos em 1967, e que chegou ao Brasil em 1969, alcançando, num período de 30 anos, 90\% das dioceses brasileiras (JURKEVICS, 2004; CARRANZA, 2009). As práticas religiosas deste movimento são influenciadas pelo pentecostalismo evangélico e, embora ambas as vertentes busquem maneiras de afirmar identidades próprias, existem entre elas vários pontos de convergência (RIBEIRO, 2011). Dentre estes, talvez o mais evidente seja a forma de adoração pautada na manifestação dos dons do Espírito Santo, com práticas como a glossolalia ${ }^{6}$, curas milagrosas, "repouso no espírito", exorcismos e revelações atribuídas a Deus. Esse modelo, ao ser utilizado pela RCC, oferece ao leigo a possibilidade de vivenciar os carismas e alcançar um contato direto e pessoal com o sagrado, em performances carregadas de emoção, atraindo fiéis de todos os segmentos da Igreja (CARRANZA; MARIZ, 2009).

Ao mesmo tempo que se baseia no pentecostalismo, é nele que a RCC vê o seu maior oponente religioso (RIBEIRO, 2011). A partir das últimas décadas do século XX, com a "avalanche do movimento neopentecostal dos anos 80 e 90, representados por religiões como: a Igreja Universal do Reino de Deus; a Igreja Internacional da Graça de Deus; a Renascer em Cristo; a Comunidade Evangélica Sara Nossa Terra, entre outras" (MEZZOMO, 2008, p. 4), é visível um aumento gradativo no número de evangélicos no Brasil, que passaram de 6,6\% em

\footnotetext{
${ }^{6}$ Entende-se por glossolalia o ato de falar em línguas estranhas, diferente de qualquer idioma humano que exista ou que já existiu. É também chamada de "línguas dos anjos", termo bíblico que aparece no livro de I Coríntios (ALMEIDA; SOUZA, 2013).

7 “O repouso no Espírito é considerado pelos carismáticos como um momento especial da experiência religiosa, quando o Espírito invade todo o corpo humano, rende-o de suas resistências e o torna tão livre a ponto de que nem o próprio sujeito o consegue controlar e, por isso, acaba caindo ao solo, ou seja, "repousando no Espírito"” (PEREIRA, 2009, p. 75).
} 
1980, para 15,4\% em 2000, 22,2\% em 2010 e 29\% em 2016 (IBGE, 2010; DATAFOLHA, 2016). Em contrapartida, há uma queda no número de seguidores do catolicismo, que diminuíram de 91,8\% em 1970 para 73,6\% em 2000, 64,6\% em 2010 e 50\% em 2016 (IBGE, 2010; DATAFOLHA, 2016). Ao enfrentar esse cenário religioso cada vez mais plural e agitado, onde as diversas instituições religiosas não medem esforços para "competir para converter (e converter para competir)" (PIERUCCI, 2012, p. 89), a RCC busca tanto conservar os fiéis que já estão na Igreja, quanto conter a propagação dos evangélicos (ORO; ALVES, 2013).

No entanto, a Igreja Católica demorou a reconhecer o potencial dos recursos midiáticos neste "mercado de fiéis", o que possivelmente se deu, segundo Camurça (2009a) não devido a uma negligência da instituição quanto ao desenvolvimento desses meios de comunicação, mas à associação que fazia dessas tecnologias com depravação moral e valores fúteis. Porém, no Brasil, a partir do final da década de 1990, a Igreja tomou consciência das possibilidades do uso da mídia, conforme expresso em uma orientação do Papa João Paulo II, que fala do dever do evangelizador de "adquirir um conhecimento sério da linguagem própria destes meios, para falar eficazmente de Cristo ao homem de hoje" (Vita Consecrata, 1996:99).

De acordo com Bronsztein e Alves (2014) "a mídia, cada vez mais, se faz presente na divulgação e na formação das identidades religiosas na medida em que se multiplicam as demandas e possibilidades de mudanças de credos". A RCC foi a principal frente na utilização desses recursos, tendo como resultado os eventos carismáticos de massa e as "celebridades gospel”, como o Padre Marcelo Rossi, ganhando cada vez mais espaço na esfera pública por meio da combinação entre música, lazer e oração, no intuito de "atrair os afastados" com "um novo jeito de ser católico" (CARRANZA, 2009, p. 34). Por meio desses grandes show-missas, a articulação entre mídia e religião se estabelece de forma plena (CAMURÇA, 2009a), e é iniciada uma nova fase da Igreja Católica: “o catolicismo midiático, compreendido como uma versão religiosa da sociedade de consumo que, em nome da evangelização, autoriza a Igreja a se apropriar da cultura midiática" (CARRANZA, 2009, p. 43). Assim, "as tradições são reinventadas, seus conteúdos simbólicos originais são alterados e adaptados a novos tempos e lugares" (BRANDÃO; PEIXOTO, 2016, p. 80), originando eventos como os "barzinhos de Jesus", "Cristotecas", "Carnafolias de Jesus", "Baladas Santas", entre outros, dentre os quais podemos destacar o Cristo é Nosso Show, analisado neste trabalho.

Seguindo os moldes das performances e formas de adoração difundidas pela RCC já destacados, o Cristo é Nosso Show ocorre anualmente desde 2003 em Campo Mourão, Paraná, 
município onde $69,4 \%$ da população se declara católica, em comparação a 23,8\% de habitantes evangélicos (IBGE, 2010). O evento está inserido no Calendário Oficial de Eventos do Estado do Paraná por meio da Lei Estadual 18.455/2015, e sua realização se dá pela Associação de Evangelização Cristo é Nosso Show, contando com o apoio da diocese de Campo Mourão e do Santuário Diocesano de Nossa Senhora Aparecida, além de outras entidades privadas da região. Promovendo atrações "com muita música, oração, louvor e animação" (BONETE, 2017), o porte da celebração é tamanho que, em 2015, foi entregue pela então prefeita mourãoense, Regina Dubay, numa parceria público-privado, o Pavilhão Cristo é Nosso Show, um barracão de 1,2 mil metros quadrados localizado no Parque Municipal de Exposições Getúlio Ferrari, utilizado como palco principal do evento (LORENZZO, 2015).

Para esta pesquisa, procuramos analisar a $15^{\mathrm{a}}$ edição do Cristo é Nosso Show, realizada em 26 de novembro de 2017, entre 9 e 19 horas, no local acima mencionado. Os procedimentos metodológicos empregados envolveram trabalho de campo ${ }^{8}$, que consistiu na observação do evento in loco e coleta de materiais como gravações de áudio, fotografias e entrevistas com os participantes. Com base no material levantado e nas análises realizadas, objetivamos compreender como o catolicismo incorpora os modelos contemporâneos de entretenimento, como shows com iluminação profissional e fumaça de gelo seco, gerando envolvimento de seus membros e atraindo novos seguidores, por meio de uma ressignificação atualizada da linguagem tradicional da Igreja Católica.

\section{A configuração do evento Cristo é Nosso Show}

Solidamente estabelecido no calendário da Igreja Católica da diocese de Campo Mourão, o Cristo é Nosso Show é um evento esperado por muitos fiéis, que buscam uma programação diferente daquelas consideradas convencionais, como missas, cultos e rezas semanais. A $15^{\text {a }}$ edição da festa ocorreu no dia 26 de novembro de 2017, entre 9 e 19 horas, no Parque de Exposições Getúlio Ferrari, com a expectativa de um público de cerca de 5.000 pessoas (BONETE, 2017). Os participantes, de diferentes faixas etárias, eram provindos de Campo Mourão e demais municípios da região, tendo organizado caravanas, em alguns casos com o uso de ônibus escolares municipais (MEZZOMO; PÁTARO; SEXUGI, 2018), como um dos meios de chegada ao local. As principais atrações foram personalidades do meio religioso

\footnotetext{
${ }^{8} \mathrm{O}$ trabalho de campo foi realizado por membros Grupo de Pesquisa Cultura e Relações de Poder da Universidade Estadual do Paraná, Câmpus de Campo Mourão. Para mais informações sobre o grupo, consultar: $<$ http://www.fecilcam.br/culturaepoder/>.
} 
como Frei Rinaldo, banda Tua Palavra, Irmã Zélia, Eliana Ribeiro, Thiago Brado e a dupla sertaneja Álvaro e Daniel. Além do palco no Pavilhão Cristo é Nosso Show, onde ocorreram as apresentações musicais, o evento contou com os espaços Cristo é Nosso Show Kids, a Capela do Silêncio, praça de alimentação e ambiente para comércio de itens de cunho religioso.

O espaço Cristo é Nosso Show Kids era destinado às crianças e, segundo uma das entrevistadas, foi criado com objetivo de "deixar os adultos aproveitarem o show". De maneira similar ao uso apontado por Camurça (2009a, p. 67) de "apropriações da linguagem virtual e da terminologia juvenil como estilos da evangelização carismática" em sites católicos na internet, aqui observamos o uso da palavra "kids" no nome do local. Isto confere uma roupagem mais moderna, jovem, que poderia soar mais interessante do que a palavra de mesmo significado em português às crianças que estão cada vez mais conectadas, através de diversos meios de comunicação, a formas de entretenimento importadas de países cujo idioma nativo é o inglês. Tal contato com as mídias estrangeiras pode ser exemplificado pela camiseta de uma das crianças presentes, estampada com o escudo do Capitão América, personagem de quadrinhos estadunidenses, e os dizeres "Meu escudo é Jesus", o que também pode ser uma tentativa de atrair o interesse pela religião por meio da sua mescla com itens da cultura pop. Além disso, no que diz respeito a estratégias de marketing, produtos comumente são nomeados com termos vindos de outros idiomas, como é o caso do inglês, por fazerem parte de uma língua conhecida por muitos ou por esta denotar prestígio, devido ao seu caráter global (PRADO, 2015), e o mesmo aqui parece se dar para chamar a atenção para o "produto religioso" oferecido pelo evento.

No espaço Kids, era realizada a brincadeira "dança da cadeira” (Imagem 1), estratégia utilizada pelas responsáveis para entreter as crianças e, ao mesmo tempo, ensinar sobre os santos católicos, como São Francisco de Assis e Santa Joana D’Arc, por meio de um desenho de suas representações aplicado em cada assento. Ao fim da atividade, uma das pessoas encarregadas compartilhou uma espécie de discurso formativo que, de forma interativa e simples, enfatizava a união entre as pessoas, dizendo que na vida em comunidade todos recebem ajuda do próximo. Por fim, organizou as crianças em círculo para juntos rezarem pelo "amiguinho do lado" e por "outros amiguinhos" que estavam longe, para serem "transformados pela ação do Espírito Santo”. Rezaram uma “Ave Maria” e, nesse momento, todos que estavam em volta começaram a rezar também, o que criou um “clima espiritual”. É possível notar como foi empregado um novo método na forma como os mancebos são ensinados sobre a religião, 
em que as representações dos santificados são utilizadas para uma brincadeira, sem a reverência costumeira. Contudo, a tradição é preservada no momento em que se realiza a oração da "Ave Maria", o que marca, junto às figuras dos santos, o momento como exclusivamente católico, mesmo que de uma forma renovada.

A Capela do Silêncio (Imagem 2) era o local direcionado a orações particulares, onde o Ostensório ${ }^{9}$ estava exposto antes de ser levado ao palco do show principal. Neste espaço, o ato de se ajoelhar diante do Sacramento, realizar uma breve oração e, ao sair, fazer uma genuflexão e o sinal da cruz, era comum a todos os fiéis que ali estavam, em um ritual para entrar na "presença de Deus". Algumas pessoas choravam e se prostravam com o "rosto no pó", atitude similar às encontradas nos rituais pentecostais, durante a adoração. Vale destacar que neste local havia poucas pessoas, em sua maioria concentradas no pavilhão em que ocorriam os shows. Porém, apesar da menor quantidade de fiéis e do pouco tempo que permaneciam na Capela, é notória uma grande reverência ao Santíssimo, que é considerado por eles o próprio Cristo vivo.

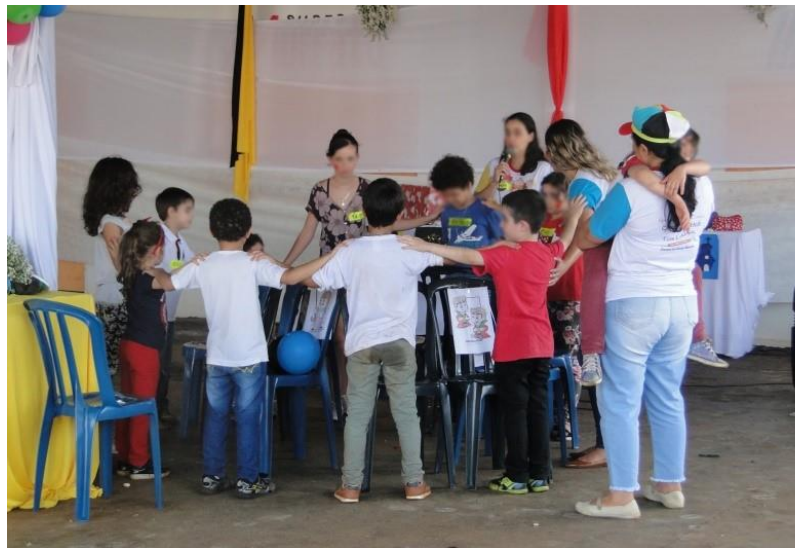

Imagem 1 - Cristo é Nosso Show Kids

Fonte: Acervo do Grupo de Pesquisa Cultura e Relações de Poder.

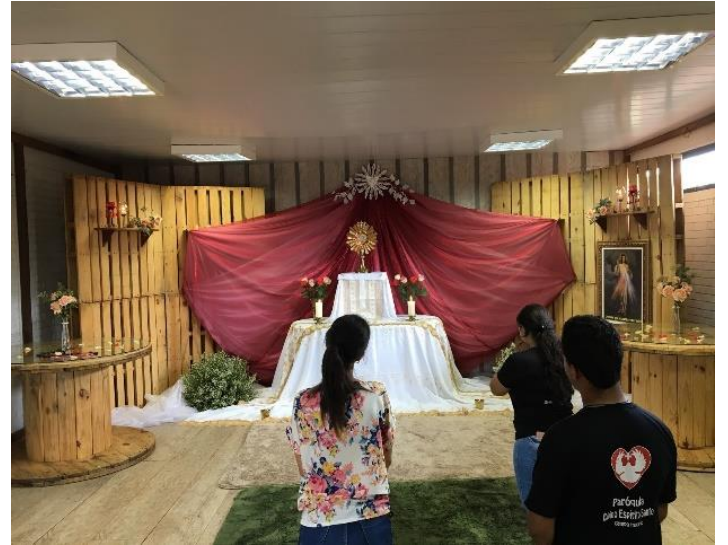

Imagem 2 - Capela do Silêncio

Fonte: Acervo do Grupo de Pesquisa Cultura e Relações de Poder.

Distante da Capela do Silêncio e bem próximo ao palco em que ocorriam os shows, havia uma pequena praça de alimentação com algumas barracas, com mesas e cadeiras, e, ao lado, um local destinado à venda de artigos religiosos como terços, bíblias, livros, camisetas com frases ou imagens de santos estampadas, escapulários, CDs gospels, entre outros (Imagem

\footnotetext{
${ }^{9}$ Receptáculo de metal, geralmente ouro ou prata, próprio para exposição da hóstia. Quando apresentado com a hóstia já consagrada, é comumente chamado de Santíssimo, o que explica as variações de nomenclatura no decorrer deste artigo.
} 
3). Assim, observamos que as formas tradicionais de se demonstrar pertencimento ao catolicismo, como rezar o terço e usar o escapulário, são acompanhadas por um modo renovado, no qual o fiel compra e ouve CDs de cantores católicos que utilizam de variados estilos musicais, do heavy metal ao sertanejo, como também por meio da utilização de bonés, bolsas, camisetas, dentre outros acessórios que, em razão das estampas que trazem em si, se tornam representações do sagrado (BRAGA, 2005; PORTELLA, 2009). Esse comércio de produtos religiosos não é visto pelos fiéis apenas como uma forma de obter lucro, mas como um meio de divulgar a doutrina, uma forma de evangelização (BORGES et al, 2015).

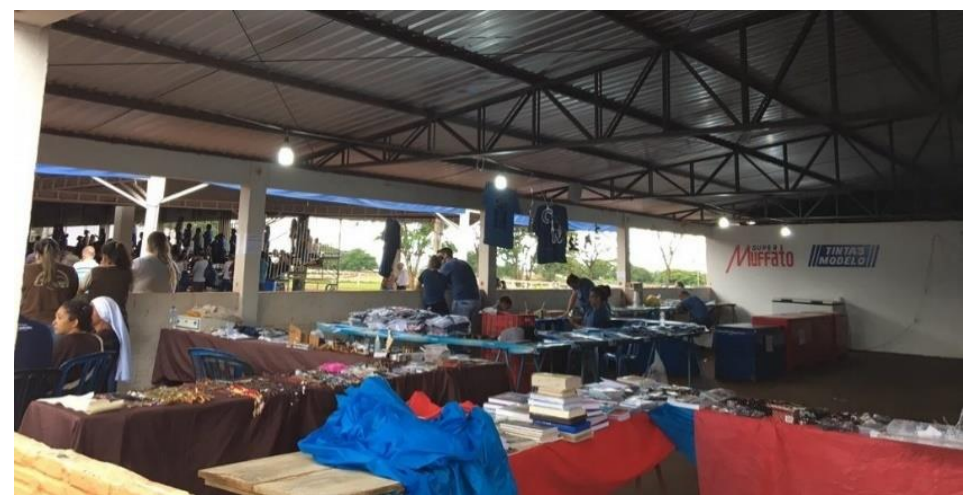

Imagem 3 - Vendas de artigos religiosos

Fonte: Acervo do Grupo de Pesquisa Cultura e Relações de Poder.

Mesmo que houvesse circulação constante nos espaços citados acima, a aglomeração do público estava no Pavilhão Cristo é Nosso Show, onde ocorriam os shows. Neste ambiente aconteceu a chamada Missa da Saúde, presidida pelo Frei Rinaldo, seguida pelas ministrações da Irmã Zélia Garcia Ribeiro - famosa pregadora da Copiosa Redenção - além de apresentações musicais da banda Tua Palavra, Álvaro e Daniel, Eliana Ribeiro e Thiago Brado. Ao lado do palco havia um altar com uma imagem de Nossa Senhora Aparecida que, embora não fosse o foco da atenção do público, se destacava graças à decoração e iluminação que a ornamentavam. A presença da imagem em um ponto de relevância no local (Imagem 4) demarca o caráter da celebração que, mesmo com suas semelhanças com o universo evangélico, é católico.

O show de Thiago Brado, com participação da Irmã Zélia, apresentou dois momentos distintos, em que observamos os rituais convencionais com uma roupagem atualizada por elementos contemporâneos. No primeiro instante ocorreram os louvores, os quais a multidão cantava junto enquanto erguia as mãos em sinal de adoração, proclamando "a Ele a glória, a Ele o louvor, a Ele o domínio, Ele é o Senhor", e "Não tenho nada a oferecer, meu Senhor / 


\section{relegens thrésketa}

Mas te dou a minha vida / É tudo o que eu tenho / Recebe o meu nada / Refaz a morada / Habita em mim”. Segundo Meyer (2015), o engajamento por meio de gestos corporais e cantos faz com que o indivíduo empregue todos os seus sentidos durante o louvor, não sendo apenas um ouvinte, mas um participante ativo da celebração, como pode ser visto na Imagem 5. Assim, essas canções trabalhavam o emocional dos fiéis, tornando a interação com o próximo momento, a chegada do Santíssimo ao palco, ainda mais profunda.

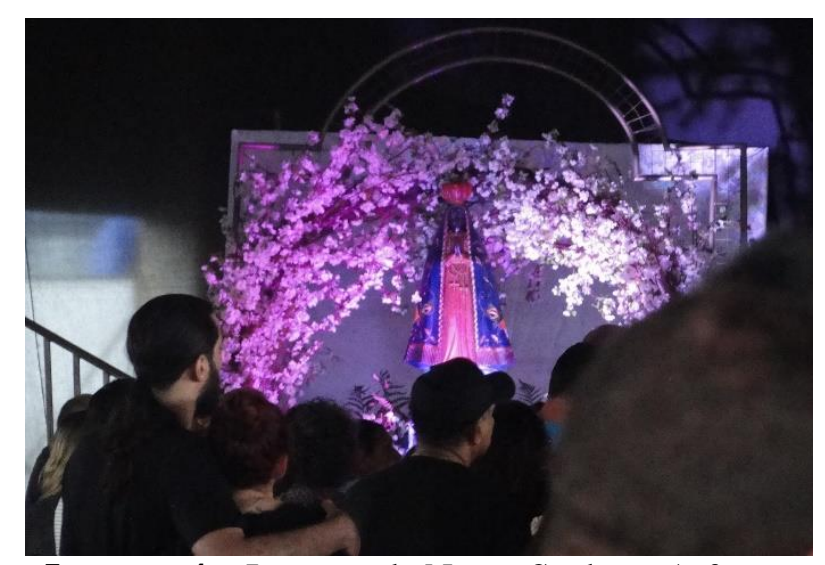

Imagem 4 - Imagem de Nossa Senhora Apa . Fonte: Acervo do Grupo de Pesquisa Cultura e Relações de Poder.

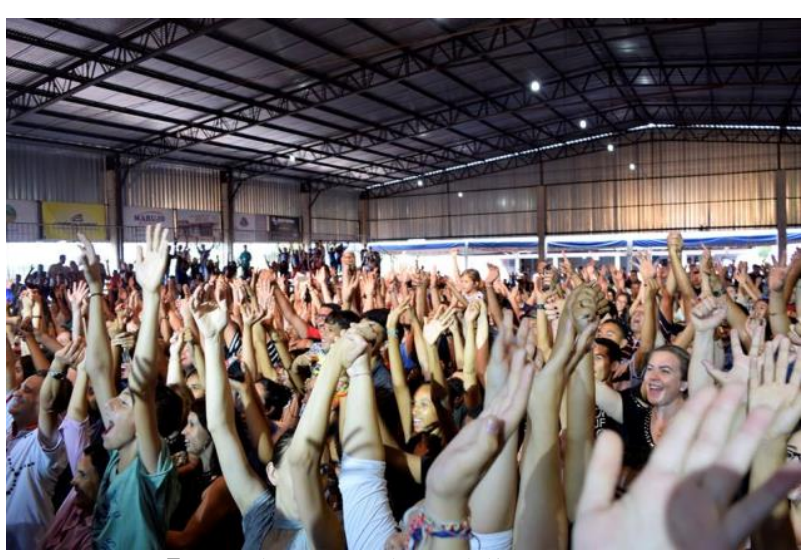

Imagem 5 - Adoração do público com gestos Fonte: Página oficial do evento no Facebook.

Enquanto ocorria o show, o Ostensório foi retirado da Capela do Silêncio e levado ao palco (Imagem 6), que contava com iluminação profissional e fumaça de gelo seco, substituindo a fumaça do incensório empregado na missa tradicional quando o Santíssimo é apresentado no altar, assim garantindo um aspecto moderno ao show e místico ao momento em que o símbolo sagrado foi exposto. Com a chegada do "Cristo vivo", a banda passou a tocar num ritmo suave, enquanto a irmã Zélia ministrava sobre cura da alma, conversão e transformação pelo Espírito Santo. Conforme seu tom de voz intensificava, a banda tocava mais alto, contribuindo para a forte comoção que envolveu o público: várias pessoas ajoelhadas, algumas chorando, muitas abraçando a pessoa ao lado ou saindo de seus lugares para unir-se com outras que estavam distantes; várias erguendo as mãos como forma de adoração. Deste modo, foi possível observar como o indivíduo, fragilizado pelas incertezas do cotidiano, busca nesses momentos uma "validação" de suas emoções em meio a um grupo que partilha de sentimentos e experiências similares (CAMURÇA, 2009b). 


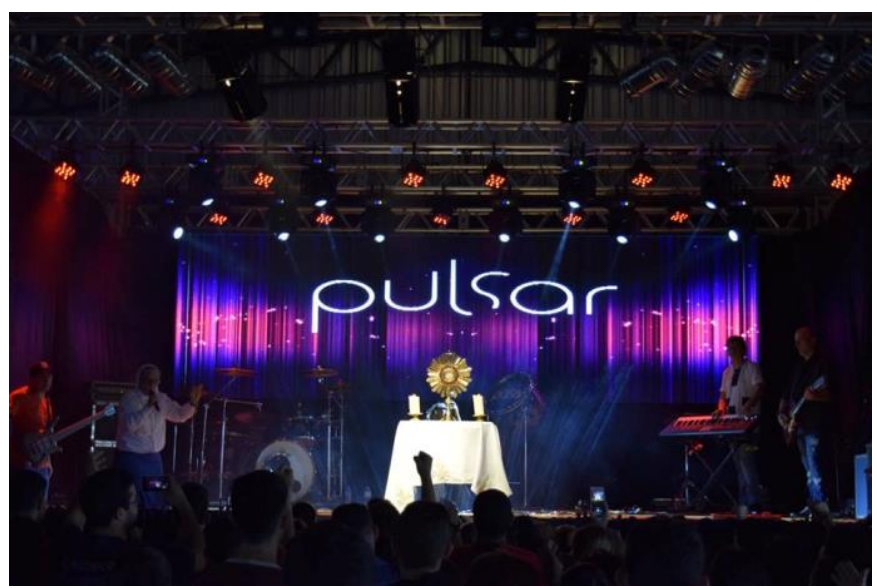

Imagem 6 - Exposição do Ostensório

Fonte: Página oficial do evento no Facebook.

Durante esse êxtase, a fórmula de adoração convencional ao Santíssimo foi pronunciada: irmã Zélia dizia "graças e louvores se deem a todo momento" e o público respondia em uníssono "ao santíssimo e diviníssimo sacramento", se mostrando muito emocionado. Com isso, notamos como a combinação entre música e ministração sensibilizou os presentes, conferindo a percepção de que a palavra era direcionada de forma particular aos fiéis, como se Deus falasse com eles. A relação entre o Ostensório, um objeto sacro tradicional, e um show "gospel-pop", que envolve e une o público, demonstra que, como coloca Meyer (2009, p. $\left.2^{10}\right)$, "uma das razões pelas quais a religião continua sendo uma força vital e atrativa está exatamente em sua propensão a se transformar por meio da incorporação de novas mídias e por se dirigir a indivíduos e conectá-los de novas maneiras". Desta maneira, podemos perceber como os rituais carismáticos, ao recorrer a elementos de caráter midiático, geram uma forma renovada de engajamento dos fiéis, resultando em uma experiência emocional e de intimidade com o sagrado.

\section{Percepções dos participantes do evento}

A partir das entrevistas realizadas com os participantes do Cristo é Nosso Show, é possível observar como estes são alcançados pelo carismatismo católico, em uma movimentação que não apenas contribui para manter o rebanho que já está na Igreja, mas também trazer novas ovelhas para o aprisco (ORO; ALVES, 2013). Assim, averiguamos que a

\footnotetext{
${ }^{10}$ Tradução livre: "one of the reasons why religion remains a vital, appealing force lies exactly in its propensity to transform by incorporating new media and addressing and linking people in new ways" (MEYER, 2009, p. 2).
} 
performance carismática é um atrativo significante para os fiéis, que buscam algo além das missas e demais maneiras convencionais de expressar a religiosidade, o que pode ser demonstrado por meio de algumas respostas que recebemos ao questionarmos os participantes acerca de suas motivações para comparecer ao evento.

É caso de Joana ${ }^{11}$ (2017), de aproximadamente 50 anos, que apontou um certo caráter cansativo e repetitivo que a missa tradicional assume: "parece que vai ficando uma coisa que vira rotina, a celebração da missa... [...] porque só a Ave Maria, o Pai Nosso, a Santa Missa, é importante para a nossa vida, sim, mas eu acho que a gente tem que se aprofundar mais [buscando pregações diferentes]". Tiago (2017), filho da entrevistada, de aproximadamente 20 anos de idade, completa que há “outros jeitos de louvar a Deus, de agradecer e rezar, não só na missa, naquela rotina [...] porque tem muito jovem que você chama para ir à missa, o cara não vai, a pessoa não vai. Você chama pra vir aqui, ele gosta", expondo a natureza evangelística, e até mesmo o maior alcance que o evento possui em relação aos compromissos dominicais.

Porém, observamos uma certa hesitação dos fiéis em assumir esta afeição pelas formas modernas do catolicismo em detrimento da liturgia convencional. Ao perceber a grande ênfase que atribuíam aos shows, Joana (2017) indicou a importância que as celebrações litúrgicas possuem, dizendo que a missa é algo "que a gente nunca deve esquecer, porque a missa tem a eucaristia, né? Que é Jesus vivo pra quem acredita, né?”. De maneira similar, ao mesmo tempo em que disse haver a necessidade da celebração carismática para um "aprofundamento" na crença, também se mostrou emocionada com a presença do Santíssimo no show. Ao nos depararmos com tal comportamento, podemos inferir que, embora o modelo regular de culto possa ser considerado por alguns enfadonho, aqueles que buscam os modos contemporâneos de adoração continuam a se mostrar tocados por elementos tradicionais.

Mesmo que atribuam importância aos rituais convencionais, como no caso de Pedro (2017), de aproximadamente 50 anos de idade, que alegou ser Jesus a sua motivação para comparecer ao show - afirmação esta realizada enquanto apontava com o dedo para o Ostensório de maneira quase teatral -, é notório como o carismatismo recebe destaque de seu público. Um dos aspectos que motivou a entrevistada Joana (2017) a participar do evento foi, segundo ela, a diferença entre a homilia rotineira do padre no culto dominical e a pregação do Frei no evento. De forma similar, Felipe (2017), de aproximadamente 50 anos, disse que "o

\footnotetext{
${ }^{11}$ Neste trabalho, atribuímos nomes fictícios aos entrevistados a fim de preservar sua identidade.
} 
padre explica de uma maneira e o pregador explica de outra maneira. Não sei qual a diferença, só que o padre tem um carisma que ele tem que levar para o povão... o pregador, ele já vai mais na essência das pessoas". Presente nas pregações carismáticas, "a linguagem neotradicional pós-moderna difere-se da linguagem tradicional, uma vez que visa responder à situação existencial das pessoas que se destinam a mensagem de Jesus e não tanto ao aspecto literário de sua vida" (FILHO et al, 2016, p. 247), ao contrário da homília, que possui um caráter mais teológico e literário.

Os motivos que levam os fiéis a participarem desses eventos carismáticos "giram quase sempre em torno de uma religiosidade de caráter fortemente emocional" (RIBEIRO, 2011, p. 179). Isso é visível na fala de Bartolomeu (2017), de aproximadamente 30 anos de idade, que disse buscar no Cristo é Nosso Show o carisma porque "o fervor é maior", a presença de Deus é mais sentida, "esquenta mais o coração [...], cada um aceita Deus de uma maneira, a minha maneira de adorar, a que me prende, é essa". Disse também que vai à missa, mas que aquilo que realmente procura é o carisma. Percebemos com esse discurso que o entrevistado não despreza a maneira convencional de adoração, mas prefere nitidamente a forma renovada.

Esse jeito "atualizado" de ser católico tem como um de seus objetivos alcançar aqueles que ainda não seguem a religião (ORO; ALVES, 2013), potencial ilustrado pelo jovem Tomé (2017), de aproximadamente 16 anos de idade, que estava no evento a convite de sua professora que realizava trabalhos na igreja. Disse ter gostado da celebração, e que sua frequência nas missas dominicais é esporádica: "eu vou, assim... Eu vou participar... Vou um domingo sim, outro também, às vezes não [risos], quando dá, a gente vai”. Além disso, embora tenha afirmado que sua participação no Cristo é Nosso Show se deu devido ao fato de não ter outra coisa para fazer no domingo, e não por uma motivação mais profunda, tal contato com a religiosidade pautada no evento pode ter contribuído para trazê-lo definitivamente, mesmo que aos poucos, para uma vida ativa no catolicismo.

De forma análoga, Felipe (2017) e Pedro (2017), que são pregadores em suas comunidades de origem, nos convidaram a participar de um grupo de oração, afirmando que "você ir na missa e ser catequista é totalmente diferente de ser do grupo de oração". Para enfatizar a diferença, Felipe expôs sobre o poder do Espírito Santo, contou seu testemunho de conversão, e disse que não poderia deixar de falar conosco naquele momento, porque Deus o movia a falar, nos convidando mais uma vez para participar do grupo, de forma insistente. 
Observamos, aqui, a utilização de atributos carismáticos para que possíveis "desviados" conseguissem se convencer de que frequentar um grupo de oração da RCC seria uma experiência mais satisfatória do que participar somente dos ritos habituais e, de alguma forma, passassem a fazer parte da Igreja.

No decorrer da entrevista, Felipe (2017) destacou os dons e o batismo com o Espírito Santo enquanto nos "evangelizava", dizendo que as características da RCC de fazer gestos, de "orar um pouco mais alto", são formas de ajudar as pessoas a buscarem a Deus. E frisou: "Gosto de falar na íntegra: Renovação Carismática Católica. É Católica. É um pouco diferente? É. Mas é Espírito Santo dentro da Igreja Católica". Por meio deste comentário podemos perceber que, devido às semelhanças do carismatismo católico com as práticas evangélicas, "há uma tendência no interior do catolicismo de fixação de fronteiras entre a RCC e o pentecostalismo, acionando, para tanto, certos elementos simbólicos, o mais importante deles sendo a devoção à Virgem Maria" (ORO; ALVES, 2013, p. 125). Como já dito, ao lado do palco havia uma imagem de Nossa Senhora Aparecida, que "já é um elemento identitário" (RIBEIRO, 2011, p. 175) que indica a personalidade católica do evento.

Porém, não são apenas os carismas do Espírito do Santo que atraem os fiéis: o carisma das "estrelas gospel” que participam do Cristo é Nosso Show também se mostra como um grande chamativo para o público. Após a apresentação de Thiago Brado, observamos certa tietagem, na maior parte por adolescentes, para tirar fotos e pegar autógrafos com o cantor, o que resultou em uma fila considerável atrás do pavilhão, onde estava instalado o camarim do artista. Aqui, entrevistamos duas jovens, de idade entre 14 e 16 anos, que disseram com animação que a atração que mais tinham esperado para ver havia sido o famoso, sendo aquele já o segundo show dele que frequentavam.

O comportamento de fã não se restringe aos mais jovens, como mostram os exemplos a seguir, resultantes das falas de duas entrevistadas, ambas na faixa dos 40-50 anos de idade: Joana (2017) contou, empolgada, sobre a foto que tirou com a dupla Álvaro e Daniel e, quando questionamos Andréia (2017) sobre quais eram as suas motivações para comparecer ao evento, respondeu que veio pelo show e que estava muito animada para ver a apresentação de Eliana Ribeiro, acrescentando que já havia tirado fotos com a Irmã Zélia e com Frei Rinaldo. Deste modo, é possível perceber o tratamento de popstars recebido por esses famosos do cenário católico. Eis, então, que surge a questão sobre quem e $o$ quê está sendo adorado pelos fiéis 
nessas apresentações: a palavra religiosa que é apresentada, o indivíduo que a exprime, ou ambos? A ideia principal do público é a adoração a Deus, mas a intensidade desta, analisada externamente, muitas vezes parece inferior àquela dedicada à celebridade.

Diante do exposto, foi possível observar como o catolicismo se apresenta com uma linguagem reconfigurada pautada no contemporâneo, que tem sido bem aceita pelos participantes do evento, e vista por eles como uma forma de fugir da rotina, mesmo que assumam isso com certa hesitação. Além disso, o divino parece compartilhar a atenção dos "fãs fiéis" com os popstars, que podem ser considerados como mediadores do sagrado pelo público, gerando filas para tirar fotos e ganhar autógrafos, similarmente ao que ocorre no meio secular.

\section{Considerações finais}

Mediante a análise da $15^{\text {a }}$ edição do evento Cristo é Nosso Show, foi possível perceber que os shows foram as atividades mais procuradas pelos fiéis. Estes momentos, fazendo uso de artifícios modernos em confluência com traços tradicionais, são capazes de proporcionar aos participantes um engajamento emocional e íntimo com o sagrado. Assim, a Igreja passa a transmitir uma imagem de um catolicismo rejuvenescido, que utiliza de uma ampla variedade de ações para conquistar e agregar fiéis, numa junção entre devoção e espetáculo, o que resulta em novas experiências religiosas e diversifica a oferta religiosa tradicional (CARRANZA, 2009).

A partir das entrevistas realizadas, é observável certa preferência dos fiéis à forma carismática de adoração, mesmo que assumam tal predileção com alguma hesitação, enquanto as missas dominicais são descritas como "rotineiras". Podemos também destacar a natureza evangelística do evento, que atrai aqueles que não estão ligados efetivamente à Instituição, seja em função das experiências emocionais proporcionadas pela adoração carismática ou do entretenimento.

Além disso, notamos uma preocupação em fixar uma fronteira entre o catolicismo renovado e o pentecostalismo (ORO; ALVES, 2013), como pode ser percebido na presença de uma imagem de Nossa Senhora Aparecida ao lado do palco dos shows, indicando o perfil católico da celebração, e na fala dos pregadores da RCC entrevistados, que frisam o fato de o movimento se tratar da manifestação do Espírito Santo dentro do catolicismo. 
Por fim, se Paulo de Tarso afirma que "tudo se fez novo", na renovação do catolicismo "as coisas velhas (não) passaram", mas continuam presentes, compartilhando o espaço com o moderno. Assim, a combinação entre o tradicional e o renovado produz novas formas de "ser católico" que, ao mesmo tempo, não perdem elementos estabelecidos na longa duração pela Igreja: "eis que (quase) tudo se fez novo".

\section{Referências}

BONETE, C. Cristo é Nosso Show começa com Missa da Saúde com Frei Rinaldo. Tribuna do Interior. Publicado em: 25 nov. 2017. Disponível em: $<$ https://www.tribunadointerior.com.br/noticia/cristo-e-nosso-show-comeca-com-missa-dasaude-com-frei-rinaldo>. Acesso em: 19 jun. 2019.

BORGES, A. F. et al. Empreendedorismo religioso: um estudo sobre empresas que exploram o nicho das religiosidades. Revista de Administração Contemporânea, Rio de Janeiro, v. 19, n. 5, p. 565-589, set./out. 2015.

BRANDÃO, V. B. G.; PEIXOTO, M. C. L. Religião em movimento: festas religiosas de agosto em Montes Claros, Minas Gerais. In: MEZZOMO, F. A.; PÁTARO, C. S. O.; HAHN, F. A. (Orgs.). Religião, cultura \& espaço público. Campo Mourão: Fecilcam, 2016, p. 79-96.

BRAGA, A. M. C. Catolicização do cotidiano, cotidianização do catolicismo: Mídia, novas práticas religiosas e individualidade entre telespectadores e ouvintes da rádio e TV católica Canção Nova. Numen, Juiz de Fora, v. 8, n. 2, p.61-78, jul./dez. 2005.

BRONSZTEIN, C. P.; ALVES, M. L. B. Mega-eventos e espetáculos religiosos: novas singularidades na sociedade de consumo. Animus, Santa Maria, v. 13, n. 26, jul./dez. 2014.

CAMURÇA, M. A. Tradicionalismo e meios de comunicação de massa: o catolicismo midiático. In: CARRANZA, B.; MARIZ, C.; CAMURÇA, M. (Orgs.). Novas comunidades católicas: em busca do espaço pós-moderno. Aparecida: Ideias \& letras, 2009, p. 59-78.

Memória e narrativas da Renovação carismática Católica. Revista Brasileira de História das Religiões, Maringá, v. 5, n. 15, p. 161-168, jan. 2013.

CARRANZA, B. Perspectivas da neopentecostalização católica. In: CARRANZA, B.; MARIZ, C.; CAMURÇA, M. (Orgs.). Novas comunidades católicas: em busca do espaço pós-moderno. Aparecida: Ideias \& letras, 2009, p. 33-58.

CARRANZA, B.; MARIZ, C. Novas comunidades católicas: por que crescem? In:__(Orgs.). Novas comunidades católicas: em busca do espaço pós-moderno. Aparecida: Ideias \& letras, 2009, p. 139-170. 
DATAFOLHA. 44\% dos evangélicos são ex-católicos. Disponível em: <http://datafolha.folha.uol.com.br/opiniaopublica/2016/12/1845231-44-dos-evangelicos-saoex-catolicos.shtml>. Acesso em: 19 jun. 2019.

FILHO, D. M. et al. Linguagens sobre Jesus: um resumo da obra de J. B. Libanio. Teoliterária, [s.I.], v. 6, n. 12, p. 246-251, jul./dez. 2016.

GIUMBELLI, E. Cultura pública: evangélicos e sua presença na sociedade brasileira. In: GIUMBELLI, E. Símbolos Religiosos em Controvérsias. São Paulo: Terceiro Nome, 2014, p. 189-208.

HERVIEU-LÉGER, D. O peregrino e o convertido: a religião em movimento. Petrópolis: Vozes, 2008.

HOBSBAWN, E.; RANGER, T. A invenção das tradições. Rio de Janeiro: Paz e Terra, 2006.

IBGE. Censo demográfico 2010. Disponível em: <https://censo2010.ibge.gov.br/noticiascenso ?id=3\&idnoticia=2170\&view=noticia $>$. Acesso em: 19 jun. 2019.

JURKEVICS, V. I. Renovação Carismática Católica: reencantamento do mundo. História: questões \& debates, Curitiba, v. 40, n. 1, p. 121-134, jul./dez. 2004.

LOREnZZO, F. Pavilhão do Cristo é nosso Show é entregue no Parque de Exposições. Tasabendo Geral. Publicado em: 10 jul. 2015. Disponível em: $<$ https://tasabendo.com.br/geral/pavilhao-do-cristo-e-nosso-show-e-entregue-no-parque-deexposicoes/>. Acesso em: 19 jun. 2019.

MENDES, V. H. Vaticano II: a modernidade da Igreja em um contexto de mudanças. Encontros Teológicos, Florianópolis, ano 27, n. 2, p. 139-163, maio/ago. 2012.

MEYER, B. From Imagined Communities to Aesthetic Formations: Religious Mediations, Sensational Forms, and Styles of Binding. In: MEYER, B. (Org.). Aesthetic Formations: Media, Religion, and the Senses. New York: Palgrave Macmillan, 2009.

Mediação e Imediatismo: formas sensoriais, ideologias semióticas e a questão do meio. Campos: Revista de Antropologia, Curitiba, v. 16, n. 2, p. 145-164, 2015

ORO, A. P. ALVES, D. Renovação Carismática Católica: movimento de superação da oposição entre catolicismo e pentecostalismo? Religião e Sociedade, Rio de Janeiro, v. 33, n.1, p. 122144, jan./jun. 2013.

PARANÁ. Lei Estadual n. 18.455, de 14 de abril de 2015. Inserção no Calendário Oficial de Eventos do Estado do Paraná do evento Cristo é Nosso Show. Diário Oficial [do] Estado do Paraná, Curitiba, PR, 16 abr. 2015. p. 03. 
PEREIRA, E. O espírito da oração ou como os carismáticos entre em contato com Deus. Religião e Sociedade, Rio de Janeiro, v. 29, n. 2, p. 58-81, jul./dez. 2009.

PIERUCCI, A. F. O crescimento da liberdade religiosa e o declínio da religião tradicional: a propósito do censo 2010. Anuac, Cagliari, v. 1, n. 2, p. 87-96, nov. 2012.

PORTELLA, R. Medievais e pós-modernos: a Toca de Assis e as novas sensibilidades católicas juvenis. In: CARRANZA, B.; MARIZ, C.; CAMURÇA, M. (Orgs.). Novas comunidades católicas: em busca do espaço pós-moderno. Aparecida: Ideias \& letras, 2009, p. 171-194.

PRADO, N. C. O uso do inglês em contexto comercial no Brasil e em Portugal: questões linguísticas e culturais. São Paulo: Editora UNESP, 2015.

RIBEIRO, A. L. Uma tipologia do pentecostalismo católico: a RCC em ondas. Fragmentos de Cultura, Goiânia, v. 21, n. 4/6, p. 171-186, abr./jun. 2011.

SANCHEZ, W. L. Igreja Católica e liberdade religiosa: a renovação desencadeada pelo Concílio Vaticano II. Rever, ano 17, n. 3, p. 123-138, set./dez. 2017.

SANTA SÉ. Constituição Apostólica Humanae Salutis do Sumo Pontífice João XXIII para a Convocação do Concílio Vaticano II. 1961. Disponível em: <https://w2.vatican.va/content/john-xxiii/pt/apost_constitutions/1961/documents/hf_jxxiii_apc_19611225_humanae-salutis.html>. Acesso em: 19 jun. 2019.

SANTA SÉ. Exortação apostólica pós-sinodal Vita Consecrata do Santo Padre João Paulo II ao episcopado e ao clero, às ordens e congregações religiosas, às sociedades de vida apostólica, aos institutos seculares e a todos os fiéis sobre a vida consagrada e a sua missão na Igreja e no mundo. 1996. Disponível em: <http://www.vatican.va/roman_curia/congregations/ccscrlife/documents/hf_jpii_exh_25031996_vita-consecrata_po.html>. Acesso em: 13 jun. 2018.po.html>. Acesso em: 19 jun. 2019. 